\title{
Reflexiones en torno a la variación léxica en el ámbito hispánico y la traducción*
}

\author{
Reflections on the lexical variation \\ in the Spanish-speaking world and its relation \\ with translation
}

Erik Daniel Franco Trujillo El Colegio de México, Centro de Estudios Lingüísticos y Literarios efranco@colmex.mx 


\section{Resumen}

En esta nota presento algunas reflexiones generales en torno al fenómeno de la variación léxica en el ámbito hispánico y su problemática en las prácticas traductoras en el mundo hispanohablante. Para ello, parto de una caracterización general de la variación como fenómeno lingüístico y expongo la situación actual del español en el mundo; posteriormente, doy cuenta de las tradiciones verbales y géneros discursivos de los que se valen los hispanohablantes en el dinamismo de sus prácticas lingüísticas, para finalmente establecer los principales problemas de la variación léxica como concepto teórico y delinear algunas de sus repercusiones tanto en el quehacer traductor como en la traducción audiovisual en particular.

Palabras clave: variación léxica; traducción; español estándar; tradiciones verbales; traducción audiovisual

\section{Abstract}

This note outlines some general reflections on lexical variation in the Spanish language and the difficulties involved as regards to translation to Spanish. First, a general characterization of variation as a linguistic phenomenon is introduced, as well as the current situation of the Spanish language around the world. Then, the verbal traditions and some discursive genres used by Spanish speakers as part of their linguistic practices are described. Finally, the main issues of lexical variation as a theoretical concept are established, aiming to delineate some of its repercussions in certain translating tasks in general, and in audiovisual translation in particular.

Keywords: lexical variation; translation; standard Spanish; verbal traditions; audiovisual translation 


\section{Introducción}

Que existe igual número de formas diversas de hablar una lengua como hablantes de la misma, resulta un hecho patente e incontrovertible tanto para el individuo común como para los especialistas y estudiosos del lenguaje. Todos, por el simple hecho de afincar nuestra experiencia del mundo en una lengua determinada y desenvolvernos en sociedad, experimentamos cierta fascinación, extrañamiento, curiosidad o rechazo ante ciertas formas de expresión verbal que identificamos, por diferentes razones, como propias o ajenas. Las consecuencias teóricas y metodológicas que se desprenden de esta variación y variedad de los actos verbales en las comunidades de habla - así como como en el devenir histórico de las lenguas humanas-, muestran las dificultades que enfrenta la lingüística al intentar establecer con claridad, y en toda su complejidad, su objeto de estudio. Del paradigma estructuralista más ortodoxo hasta las gramáticas formales más sofisticadas, hemos heredado una concepción abstracta y autocontenida de los hechos lingüísticos donde la dimensión sociohistórica de las lenguas y su consiguiente variación adquiere, en el mejor de los casos, un interés marginal o francamente anecdótico. Han sido disciplinas como la dialectología, la etnografía de la comunicación, la sociolingüística y el análisis del discurso, las que han abierto el camino para valorar, comprender, describir y explicar la variación intrínseca que acontece al interior de los sistemas lingüísticos.

Si se busca partir de un marco de referencia en el que la variación se asuma como un hecho consustancial a las lenguas humanas, debemos reconocer que resulta infructuoso adherirse a una concepción abstracta, rígida y estrecha de lo que significa saber hablar una lengua, pues durante el proceso de adquisición de la lengua materna no nos apropiamos solo de un conjunto de reglas

Una primera versión de este trabajo fue leída en una conferencia el día 24 de octubre de 2018 en la Universidad Autónoma de Baja California, en Ensenada, México. 
fonológicas, morfológicas, sintácticas y semánticas para producir y comprender un sinfín de mensajes que nunca antes hemos escuchado, como se plantea en la competencia lingüística chomskiana (Chomsky, 1965), sino que aprendemos a comunicar nuestras necesidades, inquietudes e intereses y a desarrollarnos como individuos poseedores de una lengua en situaciones de uso puntuales que se rigen por su pertinencia significativa en una comunidad de habla (Lara, 2009a). De modo que hablar una lengua implica un conocimiento profundo que nos permite distinguir cuándo, cómo, dónde, con quién y de qué hablar como observa Hymes (1995).

Estas formas o modos de hablar que vamos adquiriendo como miembros de una comunidad lingüística nos preparan para desenvolvernos con soltura, congruencia y naturalidad en diversas situaciones comunicativas, pues es bien sabido que no es lo mismo conversar con los amigos que exponer un tema a profundidad frente a un auditorio; que no es lo mismo dialogar con el jefe durante una junta de trabajo, que con la pareja o con los padres. Visto desde esta perspectiva, la facultad de hablar trasciende el plano neurofisiológico para entrar en el plano sociocultural donde la variación adquiere su verdadera proyección comunicativa y simbólica.

Con esto en mente, en esta nota presento algunas reflexiones teóricas generales en torno al fenómeno de la variación léxica en el ámbito hispánico y a sus repercusiones en las prácticas traductoras en el mundo hispanohablante.

\section{La variación lingüística}

En primer lugar, considero importante tener una idea clara sobre lo que habrá de entenderse por variación lingüística. De acuerdo con el Diccionario de términos clave de ELE (Martín, 2008), la variación lingüística es "el uso de la lengua condicionado por factores de tipo geográfico, sociocultural, contextual o histórico", de manera que cualquier nivel de descripción linguiística, llámese fonemas, morfemas, palabras, estructuras sintácticas, etcétera, está sujeto a algún tipo de variación. 
La geografía lingüística, como la rama de la dialectología que se encarga de estudiar la distribución y difusión espacial de los hechos lingüísticos (Coseriu, 1977), permite dar cuenta de la variación desde un punto de vista horizontal o diatópico. Como hispanohablantes, esta variación geográfica, especialmente la que se relaciona con la pronunciación de ciertos elementos lingüísticos y con el léxico, se nos manifiesta abiertamente cuando interactuamos con algún individuo proveniente de algún otro país de habla hispana, ya sea peruano, mexicano, argentino, cubano, español, chileno, venezolano, etcétera. De hecho, nuestra percepción de esta diferencia es tan clara que no tenemos mucha dificultad para imitar lo que llamamos otros acentos. Ciertamente, esta variación diatópica de la lengua también la encontramos al interior de un país como México donde, por ejemplo, un hablante de español mexicano en Mérida, Yucatán, utiliza la palabra wixar para referirse al acto de orinar; puede recurrir al verbo encampanarse para hablar de que alguien se ha enamorado o está entusiasmado por algo o bien prefiere el mayismo xich' para denominar lo que en otras latitudes de la República Mexicana se conoce como 'sobaco' o 'axila'. De la misma manera, un hablante de español en Tijuana que al decir que uno anda bichi significa que está desnudo, donde un güíner es un ladrón o alguien abusivo, o donde para hacer referencia a un amigo, camarada o compañero, es común escuchar el anglicismo jomi. En resumidas cuentas, la variación geográfica de la lengua es un tipo de variación fácilmente perceptible por los hablantes.

Sin embargo, cuando pensamos en las lenguas humanas como diasistemas (Weinreich, 1954), resulta que su esfera geográfica representa solamente una de las dimensiones de la variación. Así, la sociolingüística proporciona las herramientas necesarias para atestiguar lo que algunos denominan variación vertical de la lengua, cuya naturaleza se encuentra condicionada por las circunstancias socioculturales, los factores expresivos y las situaciones comunicativas en las que los hablantes de una comunidad lingüística establecen su actividad dialógica. A diferencia de la variación diatópica, este segundo tipo de variación puede ser de dos clases: 1) social 
o diastrática, 2) estilística o diafásica, a las que bien se puede agregar la variación temática o diatécnica, sin olvidar que los significados y sus respectivas denominaciones también están sujetas a una variación temporal o diacrónica.

\subsection{La variación lingüística y la traductología}

Desde de la traductología, la problemática de la variación lingüística ha desembocado en algunas propuestas cuyo objetivo final ha sido plantear posibles alternativas para su tratamiento en la práctica traductora (Catford, 1965; House, 1977; Rabadán, 1991; Hatim \& Mason, 1997). Más allá de las particularidades de cada modelo, existe cierto consenso que establece que la variación lingüística puede englobarse a partir de dos grandes parámetros: un parámetro centrado en el uso y un parámetro centrado en el usuario (Fawcett, 2003). Esta distinción resulta esclarecedora para ponderar los niveles de complejidad en los que transita el traductor al enfrentarse al fenómeno de la variación.

De acuerdo con Agost (1998: 84), la variación según el uso debe partir de la consideración de los siguientes elementos:

a) El campo, que comprende el marco social en el que se desarrolla un acto comunicativo, el tema que en él se trata y la función que busca cumplir.

b) El tenor, que involucra el estilo que se utiliza en cierto acto comunicativo en función del contexto, el tema, los interlocutores, etcétera.

c) El modo, que implica el canal (oral, escrito, audiovisual, etcétera) que se elige para comunicar algo y que ayuda a determinar las características de ciertas prácticas discursivas.

Por su parte, la variación según el usuario (Agost, 1998: 85) se concentra en aquellos rasgos que caracterizan a los hablantes a partir de aspectos como: 
a) La variación diacrónica, debida a la evolución que cualquier sistema lingüístico tiene a lo largo del tiempo y que incluso se manifiesta de una generación a otra.

b) La variación diatópica, que refleja las diferencias lingüísticas desde una perspectiva geográfica.

c) La variación social, que se relaciona con factores sociales como el nivel educativo, el nivel socioeconómico, el sexo de los hablantes, etcétera.

d) La variación idiolectal, que se vincula con el comportamiento lingüístico individual de cada hablante.

La combinación de los diversos factores que motivan la variación lingüística ha desembocado en la propuesta de estrategias traductoras que permiten darle solución o reconocer distintas opciones para tratar esta problemática.

Por citar un ejemplo, Mayoral (1990) puntualiza la importancia de acercarse a la variación social o diastrático-diafásica en casos como el lenguaje tabú, desde su dimensión emotiva y no denotativa. De igual modo, tras reconocer que cualquier dialecto debe valorarse en sí mismo, ya que forma parte de una cultura única, baraja la posibilidad de tratar la variación geográfica o diatópica mediante enfoques como:

a) Traducir un dialecto de la lengua fuente mediante un dialecto correspondiente en la lengua meta como sugería Catford (1965).

b) Caracterizar el dialecto de la lengua fuente apelando a elementos fonéticos, léxicos y sintácticos que resulten obvios para el receptor.

c) Traducir a una lengua estándar, aunque esto resulte en la pérdida de matices semánticos y pragmáticos importantes.

A partir de estas observaciones preliminares, el caso de la variación lingüística a nivel panhispánico resulta sumamente sugerente 
si tomamos en cuenta que existen 21 Estados nacionales donde el español constituye una lengua nacional. ${ }^{1}$ Cada uno de estos dialectos es producto de circunstancias sociohistóricas particulares, por lo que conforma un sistema lingüístico integral con su propia fonología, sintaxis, léxico, normatividad, etcétera. Dadas estas circunstancias, cabe problematizar en torno a las condiciones actuales de la lengua española, antes de entrar de lleno en la variación léxica y sus repercusiones en el quehacer traductor en el ámbito hispánico.

\section{La situación actual de la lengua española en el mundo}

Como es sabido, el español es una lengua con cientos de millones de hablantes a nivel mundial. La cifra exacta, de acuerdo con la publicación Ethnologue: Languages of the World, es de 442384 990 hispanohablantes nativos. Al sumar a esta cifra los otros 70 606900 hablantes que utilizan el español como segunda lengua, tenemos un total de 512991890 hispanohablantes en la Tierra. Si consideramos que solamente 28 de las más de 6 mil lenguas documentadas en el orbe ${ }^{2}$ superan los 50 millones de hablantes, podemos hacernos una primera idea de la variación en una lengua como la española que cuenta con una enorme cantidad de hablantes y una inmensa dispersión geográfica.

\subsection{Multicentrismo y multipolaridad}

Al tomar como base las grandes zonas dialectales que propone, por ejemplo, el Corpus del Español del Siglo XXI de la Real Academia Española, tendríamos que existen al menos diez grandes zonas

1 Argentina, Bolivia, Chile, Colombia, Costa Rica, Cuba, Ecuador, El Salvador, España, Guatemala, Guinea Ecuatorial, Honduras, México, Nicaragua, Panamá, Paraguay, Perú, República Dominicana, Uruguay y Venezuela; además de Puerto Rico.

2 Véase https://en.wikipedia.org/wiki/List_of_languages_by_total_number_of_ speakers 
dialectales del español: España; México y Centroamérica; Río de la Plata; Caribe continental; Antillas; los Andes; Chile; Estados Unidos; Guinea Ecuatorial; Filipinas.

Como ha sido señalado por Lara, se trata de una lengua pluricéntrica cuya unidad y diversidad es producto de "la acción difusora de varios centros relativamente autónomos entre sî" (Lara, 2009b: 225). De manera que cada uno de los 21 Estados nacionales en los que el español constituye una lengua nacional conforma un centro del español contemporáneo. Sin embargo, agrega Lara (2009b), no debemos caer en la falsa percepción de considerar cada uno de estos centros de manera aislada; pues en este pluricentrismo de la lengua española existen centros cuya capacidad, trascendencia y alcance difusor es mayor que la de otros. Para el caso del continente americano, Oesterreicher (2002: 292) postula la existencia de tres grandes dialectos hispanos cuya importancia y acción difusora sobrepasa sus propias fronteras políticas; nos referimos, al español de México, al español de Buenos Aires y al español de los países andinos como Colombia, Venezuela, Perú, Ecuador, etcétera. Ante la justificada e imprescindible observación de que el español es una lengua multicéntrica, Lara (2009b) postula el concepto de multipolaridad, mediante el cual se sustenta la existencia de diversos centros del español contemporáneo, que a su vez conforman polos de difusión con distinto nivel de repercusión e importancia en el mundo hispanohablante. Algunos factores que participan y permiten que un centro del español constituya un polo de mayor influencia y difusión que otros son:

i. El número de hablantes que tiene esa variante.

ii. El nivel educativo y poder económico de esos hablantes.

iii. El alcance y cobertura de sus programas de radio y televisión.

iv. El número de libros originales y traducidos que se producen y se publican en una u otra variante de la lengua. 


\section{Valores que organizan la idea de la lengua española entre los hispanohablantes}

Independientemente del número de dialectos del español que se planteen, ya sea mediante criterios lingüísticos, geográficos, históricos o socioeconómicos, no deja de ser curioso observar que todos los hispanohablantes, a pesar de nuestras diferencias, tenemos por verdadero, y sin dejo de vacilación, que hablamos la misma lengua. Esto se explica, en parte, gracias a la historicidad de las lenguas; pues los seres humanos, como seres históricamente determinados, nos apropiamos de una lengua mediante la adopción de un sistema lingüístico y una serie de usos históricamente dados y transmitidos a través de otros individuos pertenecientes a la misma comunidad (Kabatek, 2007: 333).

Ciertamente, aquí cabe preguntarse cuáles son los elementos que configuran esta actitud que tenemos hacia nuestra lengua a pesar de la diversidad que la caracteriza. Nuevamente, el pensamiento del lingüista Luis Fernando Lara (2014) parece darnos una respuesta plausible al respecto. De acuerdo con este investigador mexicano, existen tres grandes valores que organizan la idea que los hispanohablantes hemos construido de la lengua española a lo largo de la historia. Estos valores son:

i. El valor del entendimiento mediante el cual los hispanohablantes, independientemente de las diferencias que existen en y entre nuestros dialectos, buscamos siempre el modo de darnos a entender y tenemos la disposición de entender al otro. En pocas palabras, somos una comunidad que se preocupa por que el otro nos entienda. Este valor apareció hacia el siglo XIII durante el reinado de Alfonso X, quien se dio cuenta de que era necesario que todas las leyes de León, Castilla y los demás reinos estuvieran escritas en una misma lengua para evitar malentendidos y poder impartir justicia. 
ii. El valor de la identidad de la lengua, instaurado como efecto de la Gramática de la lengua castellana publicada en 1492 y elaborada por Antonio de Nebrija, y mediante el cual todos los hispanohablantes nos reconocemos al identificar que la lengua ahí plasmada es la lengua que hablamos.

iii. El valor de la unidad de la lengua forjado a partir de las independencias de las colonias españolas en América. De acuerdo con Lara (2015), este valor surge gracias a Andrés Bello, quien, para impedir que el español americano se fragmentara, buscó que se mantuviera la unidad de la lengua. De manera que este valor permite evitar el uso de ciertos regionalismos que pueden impedir que los hispanohablantes de otros dialectos del español nos entiendan.

En resumidas cuentas, nuestra idea del español es una construcción histórica que se constituye a partir de estos tres valores. No obstante, como he venido señalando, cada país hispanohablante conforma un centro de difusión de la lengua al interior de su propio territorio $\mathrm{y}$ algunos de estos centros tienen mayor capacidad e influencia al exterior de sus fronteras. Por ende, el español es una lengua multicéntrica y multipolar que, a pesar de sus notables diferencias a nivel dialectal, consideramos como una misma gracias a los valores del entendimiento, de la identidad y de la unidad.

\section{La lengua española y sus géneros discursivos}

Cabe ahora delinear de qué manera ha sido abordado el fenómeno de la variación léxica en el marco de la teoría linguística y cómo se vincula esta concepción con la práctica de la traducción.

Como primer punto, es importante distinguir que, en su devenir histórico, el español se ha convertido en una lengua que se materializa y cumple diversas funciones comunicativas en distintos géneros discursivos. Autores como Wulf Oesterreicher (1997), Peter Koch (1997) y Johannes Kabatek (2007) afirman que, como ha- 
blantes de una lengua, somos educados en distintas tradiciones discursivas. Estas tradiciones discursivas podemos entenderlas como moldes de usos "convencionalizados que guían la transmisión de un sentido mediante elementos lingüísticos tanto en su producción como en su recepción" (Oesterreicher, 1997: 29).

$\mathrm{Al}$ interior de estas tradiciones discursivas existen géneros textuales que constituyen formas de expresión que se han desarrollado a lo largo del tiempo en una comunidad lingüística particular y que cabe agrupar bajo distintas categorías dependiendo de la similitud que tienen en cuanto contenido temático, composición y estilo verbal.

Si consideramos el tipo de textos que conforman el Corpus del Español Mexicano Contemporáneo (CEMC), ${ }^{3}$ podemos señalar que, en el español contemporáneo en México, es posible distinguir, al menos, los siguientes géneros textuales (Lara \& Ham, 1979):

i. Conversaciones cotidianas

a. En una lengua estándar.

b. En una lengua no-estándar.

- Textos regionales y jergas.

ii. Textos literarios

a. Novela, cuento, ensayo, teatro.

b. Literatura popular: novela rosa, historietas o cómics.

iii. Textos periodísticos

a. Reportajes, editoriales, reseñas (políticas, sociales, culturales, deportivas, policiacas, etcétera).

3 El CEMc es un corpus que ha servido como base para la elaboración del Diccionario del español de México. Se trata de un corpus cuyo objetivo era contar con una muestra representativa que permitiera reconocer y documentar la mayor cantidad del léxico del español mexicano contemporáneo. El cEMC está formado por un conjunto de 996 muestras textuales, de 2000 palabras gráficas cada una, escritas por autores mexicanos desde 1921 hasta 1974. Estas muestras textuales se encuentran agrupadas en catorce géneros que corresponden a los usos de las tradiciones verbales cultas y populares mexicanas (Lara, 2009a). 
iv. Textos científicos

a. Ciencias humanas (bibliotecología, filosofía, historia, pedagogía, educación, psicología, etcétera).

b. Ciencias sociales (antropología, arqueología, derecho, economía, geografía, sociología, etcétera).

c. Ciencias físico-matemáticas (astronomía, electricidad y electrónica, física, geofísica, matemáticas, computación, etcétera).

d. Ciencias químico-biológicas (biología, química, farmacología).

e. Ciencias administrativas (administración, contabilidad, finanzas, comercio, etcétera).

f. Arte (arquitectura, danza, artes plásticas, música, cine, etcétera).

v. Textos técnicos

a. Ingeniería (civil, industrial, química, automotriz, aeronáutica, naval, etcétera).

b. Comunicación (correo, periodismo, publicidad, mercadotecnia, radio, televisión, etcétera).

c. Oficios (agricultura, ganadería, pesca, carpintería, electricidad, etcétera).

vi. Otros:

a. Textos religiosos, discursos políticos.

Al listar algunos de los tipos de textos que podemos formular y leer como hablantes de español en la actualidad, cabe especular en cuáles de ellos la presencia de la variación léxica podría ser más recurrente o visible. Si seguimos la propuesta de Lara (2009a) de que todos los hablantes de español somos herederos de una tradición verbal culta y una tradición verbal popular que orientan nuestro comportamiento lingüístico, podemos tomar como base el modo en que suele concebirse y presentarse el léxico en los diccionarios monolingües, generales o integrales, en el mundo hispánico. Al considerar que la tradición culta es producto de las prácticas lin- 
güísticas que operan en la lengua literaria escrita y en las funciones sociales del lenguaje vinculadas con la esfera política, jurídica y científica que han sido cultivadas por las comunidades hispanohablantes durante los últimos diez siglos (Lara, 2012), tendríamos que el acervo léxico derivado de esta tradición conforma el núcleo duro de dichas obras lexicográficas y que, en principio, debiera constituir, en buena medida, el vocabulario común de los diversos dialectos del español. Dada su importancia comunicativa y prestigio social, el vocabulario que pertenece a estas esferas suele carecer de cualquier tipo de marca de uso en los diccionarios; no obstante, al establecer que una lengua está conformada como "una 'familia' histórica de modos de hablar afines e interdependientes" (Coseriu, 1981: 6) en la que se funda la variación interna que la caracteriza, la práctica lexicográfica occidental se ha servido de criterios de registro y estilo de lengua para proponer marcas como informal, familiar, popular, vulgar, ofensivo, etcétera, con el fin de indicar las condiciones de uso de una pieza léxica. Dado que esta clasificación del uso del vocabulario se define en relación con la lengua de la tradición culta, es de suponer que, al contrastar los diversos dialectos del español, sean aquellos vocablos o las acepciones que se encuentran más o menos alejados del estrato superior, que corresponde al léxico culto, los que con mayor claridad manifiesten esta variación. Si extrapoláramos los géneros textuales propuestos por el CEMC a todo el ámbito hispánico, pareciera que los textos en lengua no estándar y los que corresponden a la literatura popular representarían un buen punto de partida para reconocer y documentar las similitudes, las diferencias y la variación del vocabulario a nivel panhispánico. No obstante, los estudios en terminología prueban que también dentro de rubros técnico-científicos es común encontrar variación (Alpízar Castillo, 1997); valgan como ejemplo los casos que se presentan en el Cuadro 1.

Al pensar que los géneros textuales arriba expuestos también existen, con sus propias particularidades, en otras lenguas modernas y que, en muchos casos y por diversas razones, es necesario 
traducir la producción verbal en lenguas extranjeras al español contemporáneo, resulta legítimo cuestionarse a qué español debemos traducir.

\begin{tabular}{|c|c|}
\hline & acuarela: 'obra visual' (México) \\
\hline Variación diatópica & $\begin{array}{l}\text { vs. } \\
\text { pintura a la acuarela: 'obra visual' (España) }\end{array}$ \\
\hline Variación diacrónica & $\begin{array}{c}\text { flogisto (siglo XVIII) } \\
\text { vs. } \\
\text { oxígeno }\end{array}$ \\
\hline Variación diastrática & $\begin{array}{l}\text { nitrato de celulosa (término técnico) } \\
\text { piroxilina (término semitécnico) } \\
\text { pólvora de algodón (uso jergal) }\end{array}$ \\
\hline
\end{tabular}

Sin duda alguna, esta pregunta engloba problemas que competen al tipo de vocabulario que hay que emplear para ofrecer una posible versión de estos textos a una o más comunidades hispanohablantes. Me parece que aquí nos encontramos ante una situación que nos obliga a profundizar un poco más en el fenómeno de la variación léxica.

\section{La variación léxica y la traducción}

Hasta donde llega mi conocimiento, la variación léxica es un tema poco tratado en términos empíricos entre los especialistas del lenguaje. Si bien la sociolingüística variacionista ha forjado un largo y fructífero recorrido en lo que a la variación fónica se refiere, la concepción misma de la variación léxica parte de una dificultad de base que impide abordarla de un modo claro y satisfactorio; pues al establecer el principio de que es necesario que dos unidades léxicas puedan ser permutables en cualquier contexto sin que su significado cambie para que exista este tipo de variación, nos enfrenta con el problema de caracterizar con precisión lo que ha de entenderse por significado. Si bien pares léxicos como rápido/veloz, comen- 
zar/iniciar, romper/quebrar pueden ser sustituibles en varios contextos de uso, también es cierto que no cumplen con este principio de sustitución. Pensemos por ejemplo en casos como iniciar una computadora frente a comenzar una computadora que parece dar un sentido totalmente distinto. Debido a esta dificultad, la mayoría de los estudios sobre variación léxica suelen partir de un enfoque onomasiológico en el que se plantea la existencia de una equivalencia referencial entre dos o más palabras, aunque no exista una equivalencia pragmática o comunicativa absoluta. Desde la lingüística cognitiva (Geeraerts, Grondelaers \& Bakema, 1994) se ha propuesto la pertinencia de distinguir entre variación onomasiológica formal y variación onomasiológica conceptual. Como su nombre lo indica, la variación conceptual consiste en la posibilidad que tiene un hablante de elegir entre dos palabras distintas para introducir un mismo concepto, sin que esto suponga que ambas palabras deban tener el mismo significado. En estos casos, el hablante tiene la facultad de conceptualizar algo ya sea desde un punto de vista muy general o desde un punto de vista muy específico, por lo que se trata de una variación que implica la elección de categorías conceptuales distintas. Tomemos el caso de cereal y avena, que, aunque sepamos que su significado no es el mismo, en ciertos contextos pueden ser utilizadas indistintamente; no obstante, la avena, como un tipo de cereal, tiene un significado mucho más específico. Por su parte, la variación formal es aquella que involucra la posibilidad de nombrar un mismo referente de distintas maneras, es decir, se comparte una identidad referencial, aunque el significante sea distinto. Pensemos por ejemplo que lo que en México conocemos como playera, en España, Colombia y Costa Rica se le llama camiseta, en Argentina, Paraguay y Uruguay se le dice remera y en Chile y Bolivia, polera. Cabe señalar que, desde un punto de vista connotativo del significado, la variación formal entre dos palabras también suele implicar diferencias en cuanto a su valor emotivo, estilístico o discursivo (Collinson, 1939; Lyons, 1981): 
Cuadro 2. Diferencias de significado entre supuestos sinónimos ${ }^{4}$

\begin{tabular}{|c|c|c|}
\hline $\begin{array}{l}\text { Diferenclas } \\
\text { OBJETINAS }\end{array}$ & $\begin{array}{l}\text { X tiene un significado más general e } \\
\text { inclusivo que } Y \text {; por ende, } Y \text { es más } \\
\text { específico y exclusivo que } X\end{array}$ & $\begin{array}{l}\text { llegar vs arribar } \\
\text { poner vs colocar }\end{array}$ \\
\hline $\begin{array}{l}\text { DifERENCIAS } \\
\text { OBJETIVO-EMOTIVAS }\end{array}$ & $X$ tiene un siginificado más intenso que $Y$ & $\begin{array}{c}\text { repudiar vs rechazar } \\
\text { encabronarse vs enojarse }\end{array}$ \\
\hline \multirow[t]{3}{*}{$\begin{array}{l}\text { DIFERENCIAS } \\
\text { EMOTIVAS }\end{array}$} & $X$ tiene un significado más emotivo que $Y$ & $\begin{array}{l}\text { declinar vs rechazar } \\
\text { erigir vs construir }\end{array}$ \\
\hline & $\begin{array}{l}\text { El significado de X implica repudio o } \\
\text { censura moral mientras que el significado } \\
\text { de Y es neutro }\end{array}$ & $\begin{array}{l}\text { puto vs homosexual } \\
\text { ratero vs ladrón }\end{array}$ \\
\hline & Tiene un uso más profesional que $Y$ & $\begin{array}{l}\text { deceso (medicina) vs muerte } \\
\text { agravio (derecho) vs daño }\end{array}$ \\
\hline \multirow[t]{2}{*}{$\begin{array}{l}\text { DifERENCIAS } \\
\text { EVocativas }\end{array}$} & $\begin{array}{l}X \text { tiene un uso más literario que } Y \text { o bien } \\
X \text { es propio de la lengua escrita }\end{array}$ & $\begin{array}{l}\text { asno vs burro } \\
\text { bardo vs poeta }\end{array}$ \\
\hline & $X$ tiene un uso más coloquial que $Y$ & $\begin{array}{l}\text { chamba vs trabajo } \\
\text { carnal vs amigo }\end{array}$ \\
\hline \multirow[t]{2}{*}{$\begin{array}{l}\text { DifERENCIAS } \\
\text { DIALECTALES }\end{array}$} & $X$ es más dialectal o local que $Y$ & $\begin{array}{c}\text { chela (México) vs cerveza } \\
\text { porra (México) vs } \\
\text { hinchada (Argentina) }\end{array}$ \\
\hline & $\begin{array}{c}X \text { es o pertenece al habla infantil } \\
\text { mientras que } Y \text { no }\end{array}$ & $\begin{array}{l}\text { papi vs padre } \\
\text { guaguá vs perro }\end{array}$ \\
\hline
\end{tabular}

Sin lugar a dudas, la consideración de cualquiera de estos tipos de variación resulta relevante para la práctica de la traducción. En el caso de la variación conceptual, se ha comprobado que existe una tendencia en la traducción literaria a la simplificación léxica

4 La mayoría de los ejemplos propuestos en el Cuadro 2 fueron tomados del español de México a partir de lo que se documenta en el Diccionario del español de México (Lara, 2010). 
(Blum-Kulka \& Levenston, 1983: 119); es decir, las traducciones de este tipo de textos suelen tener menor riqueza léxica que sus originales y suelen presentar palabras de mayor frecuencia de uso y con un significado mucho más general (Toury, 1995). En este sentido, mi alumna Aura Jiménez Rivera (2020), que elaboró un estudio sobre los mecanismos traductológicos que George D. Schade, el primer traductor de El llano en llamas al inglés estadounidense, utilizó para traducir algunos vocablos —entre ellos varios mexicanismos, presentes en esta obra de Juan Rulfo-, ha encontrado esta tendencia a la generalización; es decir, el traductor ha sustituido palabras que son mucho más específicas en el texto fuente (TF), por palabras más generales en el texto meta (TM) tal y como podemos ver en los siguientes ejemplos:

(1) Aguardiente en "Talpa"

TF Por eso mientras Natalia le enjuagaba los pies con aguardiente para que se le deshincharan, le daba ánimos.

TM That's why Natalia encouraged him while she rubbed his feet with alcohol so the swelling would go down.

Donde el significado del vocablo alcohol en inglés que nos interesa en este caso resulta mucho más general que lo que significa aguardiente en español. Veamos las acepciones que corresponden a estos usos según el Merriam-Webster Dictionary (en adelante, MW) y el Diccionario del español de México (en adelante, DEM):

MW (2019, s.v. alcohol):

alcohol noun

$1 \mathrm{~b}$ ) drink (such as whiskey or beer) containing ethanol. DEM (2010, s.v. aguardiente):

\section{aguardiente $\mathrm{s} m$}

2 Bebida con alto grado de alcohol, destilada de frutas o plantas (anís, maguey, etc.), como el tequila, el mezcal, el vodka o el whisky. 
(2) Ocote en "Talpa"

TF Me acuerdo muy bien de esas noches. Primero nos alumbrábamos con ocotes. Después dejábamos que la ceniza oscureciera la lumbrada y luego buscábamos Natalia y yo la sombra de algo para escondernos de la luz del cielo.

TM I remember those nights very well. First we had some light from a wood fire, afterwards we'd let the fire die down, then Natalia and I would search out the shadows to hide from the light of the sky.

Lo mismo sucede con el vocablo ocote, un tipo particular de wood fire, como lo señala el DEM (2010: s.v. ocote):

ocote $\mathrm{s}$ m

1 Árbol del género Pinus, de la familia de las coníferas, perteneciente a distintas especies, que se caracteriza por producir mucha resina; crece en tierras altas de clima frío y alcanza de 20 a $25 \mathrm{~m}$ de altura en la mayoría de sus especies.

Pues wood fire es un fuego hecho con cualquier tipo de leña y no precisamente un ocote, conocido en inglés como Montezuma pine.

Para el caso de la variación formal, debemos pensar en la importancia que puede tener para la localización. La localización, entendida como el proceso mediante el cual se toma un producto para volverlo lingüística y culturalmente apropiado para un mercado meta en el que se espera sea utilizado y vendido (Esselink, 2000: 3), es un fenómeno complejo en el que deben intervenir expertos en distintas áreas del conocimiento como la informática, la mercadotecnia y la traducción. En su nivel lingüístico, la localización tiende a vincularse con usos del lenguaje característicos de un país, de una región, de un grupo social, de un grupo etario, etcétera. Esta estrategia de comercialización ha comenzado a ser utilizada en la industria de los videojuegos, en el doblaje de películas y en la creación de sitios de internet. De hecho, no resulta raro encontrar 
que empresas como Google, Yahoo!, Amazon, entre otras, manejen versiones localizadas de sus portales.

Sin embargo, en la industria de la mercadotecnia y la publicidad no siempre se puede recurrir a la localización como estrategia de marketing, sino que muchas veces se elaboran campañas publicitarias estandarizadas para lograr que un producto tenga un mayor alcance y repercusión (Declercq, 2011). La dimensión lingüística de la estandarización no es nada extraña para los hispanohablantes. Pensemos lo que sucede en los medios de comunicación con el denominado español estándar. Como es sabido, el proceso de estandarización de las lenguas europeas inició, en su forma escrita, con la invención de la imprenta por Gutenberg en el siglo XV, mientras que su consolidación, en su forma oral, se produjo gracias a la aparición de la radio y la televisión (Ávila, 2011). De igual modo, debemos recordar que toda lengua estándar se basa en los usos de ciertos grupos que tienen prestigio lingüístico y poder económico en una comunidad (Ávila, 2011).

De acuerdo con el Diccionario panhispánico de dudas (RAE, 2005), el español estándar se basa en los usos formales y cultos que emplean los hispanohablantes al hablar en público, que escuchamos en los locutores de radio y televisión, que leemos en los artículos y libros científicos y técnicos, y del que se valen las agencias internacionales de prensa, los estudios de doblaje, las productoras de telenovelas, etcétera. Sin embargo, a pesar de que dicho estándar aspiraría a conformar una única variante capaz de representar a todos los hispanohablantes, la realidad es que hay más de un español estándar. Por ello, Raúl Ávila (2011) reconoce la pertinencia de hablar de un español internacional que comprende tres españoles estándar distintos:

i. Un estándar $\alpha$ que corresponde, a grandes rasgos, a las variantes cultas de las ciudades de México, Bogotá y Quito, y que es el que se escucha con mayor frecuencia en los doblajes, en las telenovelas, en los anuncios y en los programas informativos. Desde un punto de vista linguiístico, 
este estándar $\alpha$ se caracteriza por no hacer la distinción entre el fonema fricativo alveolar sordo /s/ y el fonema fricativo dental sordo $/ \theta /$ y por evitar el uso de los pronombres vosotros y vos.

ii. También existe un estándar $\beta$ que depende de los usos de algunos comentaristas de países del Caribe y del Río de la Plata, caracterizado por presentar la aspiración del fonema fricativo alveolar sordo /s/ y la pronunciación del fonema fricativo palatal sonoro $/ \mathrm{j} /$.

iii. Y un estándar $\gamma$ que representa la variante estándar de España, que se caracteriza por hacer la distinción entre el fonema fricativo alveolar sordo /s/ y el fonema fricativo dental sordo $/ \theta /$ y el uso del pronombre personal de segunda persona del plural vosotros.

Me parece que en términos léxicos, y a reserva de contar con una investigación profunda al respecto, el estándar $\alpha$ es el que más claramente evita el uso de regionalismos y coloquialismos, debido al tipo de contenidos en los que se emplea y al tipo de público al que está dirigido; no obstante, en el ámbito de la traducción se observa con regularidad que las empresas que solicitan servicios de doblaje y subtitulaje suelen partir de dos grandes categorías que parecen estar orientadas, exclusivamente, por criterios comerciales. De modo que para evitar desembolsar una mayor cantidad de dinero ofreciendo versiones dobladas y subtituladas para cada país hispanohablante o, para el caso del continente americano, para más de un español estándar, las empresas se contentan con hacer la distinción entre castellano y español latinoamericano. En pocos casos, las empresas manejan manuales de estilo para compartirlos con sus traductores con el fin de tener lineamientos claros para que puedan desempeñar mejor su trabajo. A mi parecer, en la búsqueda de esta estandarización o de la búsqueda de ese español general que seguimos esperando se nos diga cuál es, se parte de una serie de principios e impresiones subjetivas más o menos explícitos que, en su afán por minimizar la variación y asegurar una 
supuesta comunicación transparente, desembocan en un español artificial que se encuentra regido por una normatividad lingüística, social y comercial.

Para entender esta noción de normatividad, es necesario hacer la distinción entre el uso de la lengua que se relaciona directamente con la manera o maneras como se habla una lengua y la norma que tiene que ver con la forma en que se juzga si un uso es correcto, incorrecto, propio, impropio, etcétera (Lara, 2009c: 47). Me parece que las editoriales encargadas de revisar y editar las traducciones literarias, así como las agencias de subtitulaje y doblaje, son lugares propicios para explorar las normas existentes que defienden ciertos usos que se estiman convenientes desde un punto de vista lingüístico, social y comercial.

\section{El caso de la traducción audiovisual}

Al consultar el manual de estilo del canal Turner International (s. f.) se señalan algunas pautas a seguir al momento de elaborar una propuesta de traducción audiovisual de sus programas. Por un lado, se explicitan algunas normas prescriptivas que afectan aspectos formales como la puntuación, la segmentación, la duración de los subtítulos, etcétera.

Por otro lado, encontramos también algunas normas de valoración social (Lara, 2009c: 62) que operan en esas áreas del vocabulario donde es esperable que exista mayor variación interdialectal, como es el caso de voces regionales, jergales, coloquiales o altisonantes. En este breve manual, aparece un apartado especialmente dedicado al tratamiento de vocabulario considerado vulgar y coloquial. Como se puede ver en el Cuadro 3, este cliente pide explícitamente evitar el uso de voces jergales o coloquiales en ciertos casos.

De igual modo, en el Cuadro 4 se hace una distinción entre aquellos usos que se consideran aceptables para traducir palabras altisonantes y aquellas palabras cuyo uso está completamente prohibido. 
Cuadro 3. Usos coloquiales prohibidos por Turner International (s. f.)

\begin{tabular}{ll}
\hline \multicolumn{1}{c}{ Incorrect } & \multicolumn{1}{c}{ CorRect } \\
\hline No a todos, pero anda cerca. & No a todos, pero se acerca. \\
No jodas. & No bromees. \\
Su novia acaba de cortar con él. & Su novia acaba de terminar con él. \\
Terminé siendo disparado & Inclusive me dispararon \\
Mierda / carajo & Maldición / demonios / diablos \\
Teta / bubis & Seno / pecho \\
Cagar: "como si me hubiera cagado" & "como si me hubiera hecho encima" \\
Paja: "le hizo una paja" & "lo masturbó" \\
Mear: "necesito mear" & "necesito orinar" \\
Piija / bolas & Pene/ testículos \\
\hline
\end{tabular}

Cuadro 4. Voces vulgares aceptadas por Turner International (s. f.)

Allowed terms (but still considered vulgar)

\begin{tabular}{ll}
\hline baboso & jerk \\
bastardo & bastard \\
boludo & asshole \\
cabrón & asshole \\
cepillar & as sexual intercourse \\
cojones & testicles \\
Cristo & Christ \\
guacho & bastard \\
hijo de... & son of a... \\
huevón & asshole (literally, big balls) \\
huevos & as testicles (when used as courage) \\
imbécil & stupid \\
Jesucristo & Jesus Christ \\
joder /iodido & joke, mess up \\
lesbiana & lesbian
\end{tabular}

Estudios de Lingǘstica Aplicada, año 38, número 71, julio de 2020, pp. 145-176 doi: 10.22201/enallt.01852647p.2020.71.905 


\begin{tabular}{|c|c|}
\hline \multicolumn{2}{|c|}{ Allowed terms (but still considered vulgar) } \\
\hline maldito & damn \\
\hline masturbar & masturbate \\
\hline mear & piss \\
\hline morón & moron \\
\hline (en/qué/de/al) pedo & $\begin{array}{l}\text { fart (also as synonym to drunk and to refer to } \\
\text { sth. pointless) }\end{array}$ \\
\hline perra & whore / bitch \\
\hline pito & $\begin{array}{l}\text { penis (when used in a familiar way, like when } \\
\text { used by kids) }\end{array}$ \\
\hline polvo & as sexual intercourse \\
\hline prostituta & prostitute \\
\hline que lo parió & as expletive \\
\hline ramera & whore \\
\hline sorete & turd (also used as insult) \\
\hline tarado & as insult \\
\hline
\end{tabular}

En la lista de palabras permitidas, encontramos casos que para los hablantes del español mexicano resultan marcadas, poco usuales o de plano desconocidas, como guacho, que mostramos en (3):

(3) guacho que de acuerdo con el Diccionario integral del español de la Argentina (DIEA) (Plager, 2008, s.v. guacho) puede significar cosas como:

1 adj COLOQuial Aplicado a una persona, que actúa con maldad y astucia, especialmente sin ninguna razón en particular.

2 adj COLOQUiAL Aplicado a una persona, que posee algo que causa envidia o que tiene cualidades admirables. 
3 adj COLOQUiAL Qué es huérfano.

$4 m$ y $f$ COLOQUial Niño que es pícaro o travieso.

Y, en México, según el DEM (2010, s.v. guacho) tiene los siguientes significados:

s y adj (Ofensivo)

1 En Sonora, persona que es originaria del centro o del sur del país, en particular de su capital, y se considera prepotente y corrupta, servil con sus superiores e indolente con sus subalternos, a lo que a veces se añade el ser morena, india o naca.

2 En el Sureste, fuereño, en particular el que se tiene por ignorante o ladrón.

3 En el Sureste, Sinaloa y el sur de Sonora, soldado raso.

De modo que, con el significado de 'bastard' que aparece en el Cuadro 4, parece que hasta cierto punto correspondería al primer significado que se registra tanto en el DIEA como en el DEM; sin embargo, según esta documentación, la palabra guacho en Argentina tiene un uso general, mientras que en México solamente parece tener difusión en el norte del país.

O el caso de huevón que, según lo señalado en el Cuadro 4 puede usarse para traducir la palabra idiot y que significa:

(4) En Argentina, según el DIEA (2008, s.v. huevón):

1 adj COLOQuial Aplicado a una persona, que actúa de manera ingenua, tonta o poco inteligente.

Sin embargo, según el DEM (Plager, 2010, s.v. huevón) tiene un significado totalmente distinto:

adj y s (Groser) Que es flojo; haragán. 
Ocurre algo similar con polvo que con el significado de 'relación sexual' sí se documenta en el DIEA (Plager, 2008), pero que no se utiliza en México, donde más bien se recurriría a la palabra cogida. Y con boludo, que con el significado de 'asshole' en español de México se utilizaría la palabra pendejo: 'que es tonto en extremo, que resulta despreciable' (DEM, 2010, s.v. pendejo).

Los ejemplos anteriores revelan que este manual se hizo pensando en el español argentino, no obstante, es también el que circula entre los traductores mexicanos que trabajan para esta empresa.

De la misma manera, en el Cuadro 4 aparecen palabras como tarado, maldito o lesbiana que, en principio, serían candidatos a formar parte del español general; no obstante, habría que estudiar sus condiciones de uso en cada dialecto del español para podernos cerciorar si efectivamente su frecuencia de uso y su significado son los mismos.

En el Cuadro 5 aparecen algunos ejemplos de palabras cuyo uso no está permitido según el manual de estilo de Turner (s. f.).

\begin{tabular}{ll} 
Cuadro 5. Voces vulgares prohibidas por Turner International (s. f.) \\
\hline Not allowed terms
\end{tabular}
$\begin{array}{ll}\text { forro } & \text { as insult (literally, a condom) } \\
\text { garchar } & \text { sexual intercourse } \\
\text { guayabo } & \text { when used to refer to the vagina } \\
\text { hoyo } & \text { when used to refer to the vagina (literally, a hole) } \\
\text { huevos } & \text { as testicles } \\
\text { joder } & \text { as sexual intercourse } \\
\text { lame-culos } & \text { ass licker } \\
\text { mamabicho } & \text { used to refer to oral sex (literally, cocksucker) } \\
\text { mamahuevos } & \\
\text { mamada } & \text { blow job } \\
\text { mamar } & \text { in a sexual content (as in oral sex) } \\
\text { mierda } & \text { shit } \\
\text { mogólico } & \text { when used as insult }\end{array}$


(continuación)

CUADRo 5. Voces vulgares prohibidas por Turner International (s. f.)

\begin{tabular}{ll}
\hline NOT allowed terms \\
\hline mono & when used to refer to the vagina (literally, a monkey) \\
orto & as asshole (stronger tan "culo") \\
\hline
\end{tabular}

Estas voces cuyo uso no es aceptable para Turner (s. f.) también se ejemplifican, en buena medida, a partir del español argentino:

(5) Según el DiEA (Plager, 2008, s.v. mogólico) con el significado de 'tonto o idiota' derivado de la acepción:

3 adj Que tiene síndrome de Down.

También se documenta en el español mexicano, pero con una variante formal: mongólico (DEM, 2010, s.v. mongólico)

2 adj. Que padece síndrome de Down.

(6) Orto como traducción para asshole, tal y como se registra en el DIEA (Plager, 2008, s.v. orto):

$1 \mathrm{~m}$ Grosero Ano.

Y que en el español mexicano no es usual, por lo que seguramente se utilizaría la palabra culo (DEM, 2010, s.v. culo):

culo s m (Grosería y Ofensivo)

2 Ano o abertura del recto que permite la salida de excremento.

Casos análogos son los de garchar para decir 'tener relaciones sexuales', cuando en México tendría que decirse coger o parchar; y forro como uso coloquial para 'preservativo' y que en México no 
tiene arraigo. Cabe señalar que, en el español mexicano, además del significado en el español general de 'capa de algún material con que se cubre por completo alguna cosa para protegerla o para ocultarla' (DEM, 2010, s.v. forro), la palabra forro, en su uso coloquial, también se utiliza para hablar de una persona físicamente muy atractiva: 'persona guapa, sensual, de cuerpo muy bien formado'.

\section{Comentarios finales}

Con estos ejemplos he querido mostrar que la mayoría de las veces, al menos en el área del subtitulaje y el doblaje, existe un claro interés por ofrecer un producto apto, claro y transparente para un público hispanohablante en el continente americano. Este cometido parece posible cuando los productos de la lengua fuente a traducir se manejan en un registro tal que se puede recurrir al vocabulario de la lengua culta de base literaria del español que en gran medida compartimos los hispanohablantes. No obstante, para aquellos casos donde se debe traducir programas en los que aparece el uso de un léxico de base popular, coloquial o vulgar, no podemos recurrir a esa tradición culta para ofrecer una única versión que satisfaga y se apegue a la naturalidad de expresión de los diversos dialectos del español. En consecuencia, la búsqueda de un español general o un español no marcado que resulte comunicativamente claro y comprensible para todas las comunidades hispanohablantes es un ideal que, desde el punto de vista de la ciencia del lenguaje, resulta insostenible, pero que, desde el punto de vista comercial, es muy redituable.

Ciertamente, ni todos los trabajos de traducción son iguales, ni todos tienen el mismo objetivo; pues es sabido que muchas decisiones traductológicas no dependen de los traductores, sino de las preferencias, gustos y prioridades de cada cliente. Sin duda alguna, se trata de un indicador que muestra que detrás de la idea del español neutro existe una política linguiística supeditada a intereses vinculados a una lógica capitalista (Iparraguirre, 2014). En el fondo, el hecho de que las empresas que requieren de servicios de 
traducción apelen a la homogeneidad como estrategia económica también es una invitación para que tanto traductores, intérpretes y estudiosos del lenguaje busquemos argumentos sólidos que permitan formar un frente común en el que los usos dialectales que se han cultivado en los diversos territorios de habla hispana sean valorados y reconocidos.

En lo personal, y en lo que compete al vocabulario, considero que el único modo de documentar y conocer el léxico común y el léxico diferencial al interior de la lengua española es dejando de lado observaciones impresionistas basadas en pocos datos o en nuestras intuiciones como hablantes, y empezar a hacer estudios descriptivos profundos. Una posibilidad sería elaborar corpus panhispánicos por género textual o bien atender al llamado de elaborar diccionarios integrales basados en metodologías compartidas en cada país hispanohablante (Lara, 1996). Para el caso particular de la traducción audiovisual en Hispanoamérica, un buen inicio sería la creación de corpus paralelos y comparables que reúnan subtitulajes elaborados por traductores de dos o más dialectos del español americano. De esa manera, sabremos, y muy probablemente comprobaremos, el modo en que la variación léxica se manifiesta en ese español latino o neutro al que los clientes apelan insistentemente, pero que son incapaces de caracterizar con claridad. Solamente con estudios de esa naturaleza podremos comenzar a ponderar, desde una perspectiva bien informada y con datos empíricos fiables, las verdaderas dimensiones de la unidad y la diversidad que caracterizan nuestra lengua a nivel léxico. Por el momento hemos de reconocer que el trabajo que queda por hacerse parece inagotable, sin embargo, nunca es tarde para dar el primer paso.

\section{Referencias}

Agost Canós, Rosa (1998). La importància de la variació lingüística en la traducció. Quaderns. Revista de Traducció, 2, 83-95.

Alpizar Castillo, Rodolfo (1997). ¿Cómo hacer un diccionario científico-técnico? Buenos Aires: Memphis. 
Ávila, Raúl (2011). El español neutro (?) en los medios de difusión internacional. En Raúl Ávila, Rodrigo Muñoz \& Carlos Garduño (Coords.), Variación del español en los medios (pp. 17-30). México: El Colegio de México.

Blum-Kulka, Shoshana, \& Levenston, Edward A. (1983). Universals of lexical simplification. En Claus Faerch \& Gabriele Kasper (Eds), Strategies of interlanguage communication (pp. 119-139). Londres: Longman.

Catford, John C. (1965). A linguistic theory of translation. Oxford: Oxford University Press.

Collinson, William E. (1939). Comparative synonymics: Some principles and illustrations. Transactions of the Philological Society, 38(1), 54-77. Coseriu, Eugenio (1977). La geografía lingüística. En El hombre y su lenguaje (pp. 103-158). Madrid: Gredos.

Coseriu, Eugenio (1981). Los conceptos de dialecto, nivel y estilo de lengua y el sentido propio de la dialectología. Lingüística Española Actual, $3(1), 1-32$.

Chomsky, Noam (1965). Aspects of the theory of syntax. Cambridge: MIT Press. Declercq, Christophe (2011). Advertising and localization. En Kirsten Malmkjoer \& Kevin Windle (Eds.), The Oxford Handbook of Translation Studies (pp. 262-274). Oxford: Oxford University Press.

Eberhard, David M.: Simons, Gary F., \& Fennig, Charles D. (Eds.) (2019). Ethnologue: Languages of the World. Twenty-second edition. Dallas: sIL International. http://www.ethnologue.com

Esselink, Bert (2000). A practical guide to localization. Ámsterdam: John Benjamins.

Fawcett, Peter (2003). Translation and language: linguistic theories explained. Manchester: St. Jerome.

Geeraerts, Dirk; Grondelaers, Stefan, \& Bakema, Peter (1994). The structure of lexical variation: Meaning, naming and context. Berlín: De Gruyter Mouton. Hatim, Basil, \& Mason, Ian (1997). The translator as communicator. Londres: Routledge.

House, Juliane (1977). A model for translation quality assessment. Tubinga: Gunter Narr.

Hymes, Dell H. (1995). Acerca de la competencia comunicativa. En Miquel Llobera Cànaves (Coord.), Competencia comunicativa. Documen- 
tos básicos en la enseñanza de lenguas extranjeras (pp. 27-47).

Madrid: Edelsa.

Iparraguirre, Carolina (2014). Hacia una definición del español neutro. Síntesis, $5,232-252$.

Jiménez, Aura (2020). Las estrategias traductológicas de los mexicanismos de El llano en llamas de Juan Rulfo en su primera traducción al inglés: un estudio lexicológico (Tesis de licenciatura). Escuela Nacional de Antropología e Historia, México.

Kabatek, Johannes (2007). Las tradiciones discursivas entre conservación e innovación. Rivista di Filologia e Letterature Ispaniche, 10, 331-348.

Koch, Peter (1997). Diskurstraditionen: zu ihrem sprachtheoretischen Status und ihrer Dynamik. En Barbara Frank, Thomas Haye y Doris Tophinke (Eds.), Gattungen mittelalterlicher Schriftlichkeit (pp. 4379). Tubinga: Gunter Narr.

Lara, Luis Fernando (1996). Por una redefinición de la lexicografía hispánica.

Nueva Revista de Filología Hispánica, 44(2), 345-364.

Lara, Luis Fernando (2009a). No "normas", sino tradiciones. En Luis Fernando

Lara (Ed.), Lengua histórica y normatividad (pp. 71-94). México:

El Colegio de México.

Lara, Luis Fernando (2009b). Pluricentrismo y multipolaridad en el español actual. En Memoria (pp. 225-235). México: El Colegio Nacional.

Lara, Luis Fernando (2009c). Normas lingüísticas: pluralidad y jerarquía. En Luis

Fernando Lara (Ed.), Lengua histórica y normatividad (pp. 47-70).

México: El Colegio de México.

Lara, Luis Fernando (Dir.) (2010). Diccionario del español de México. México: El Colegio de México.

Lara, Luis Fernando (2012). Hacia una tipología de las tradiciones verbales populares. Nueva Revista de Filología Hispánica, 60(1), 51-60.

Lara, Luis Fernando (2014). Pensar la lengua en el siglo Xxi. https://www.elcas tellano.org/news/lara-pensar-la-lengua-del-siglo-xxi

Lara, Luis Fernando (2015). Variación, multicentrismo y multipolaridad del español contemporáneo. En Luis Fernando Lara (Ed.), Temas del español contemporáneo: cuatro conferencias en El Colegio Nacional (pp. 9-29). México: El Colegio de México. 
Lara, Luis Fernando, \& Ham Chande, Roberto (1979). Base estadística del Diccionario del español de México. En Luis Fernando Lara, Roberto Ham Chande \& María Isabel García Hidalgo (Eds.), Investigaciones lingüísticas en lexicografía (pp. 7-39). México: El Colegio de México. Lyons, John (1981). Lenguaje, significado y contexto. Barcelona: Paidós.

Martín Peris, Ernesto (Dir.) (2008). Diccionario de términos clave de ELE. Madrid:

Centro Virtual Cervantes. http://cvc.cervantes.es/ensenanza/biblio teca_ele/diccio_ele/indice.htm

Mayoral Asensio, Roberto (1990). Comentario a algunas de las variedades de lengua. Sendebar, 1, 35-46.

Merriam-Webster Dictionary (mw) (2019). http://www.merriam-webster.com Oesterreicher, Wulf (1997). Zur Fundierung von Diskurstraditionen. En Barbara Frank, Thomas Haye \& Doris Tophinke (Eds.), Gattungen mittelalterlicher Schriftlichkeit (pp. 19-41). Tubinga: Narr.

Oesterreicher, Wulf (2002). El español, lengua pluricéntrica: perspectivas y límites de una autoafirmación lingüística nacional en Hispanoamérica. El caso mexicano. Lexis, 26(2), 275-304.

Plager, Federico (Coord.) (2008). Diccionario integral del español de la Argentina. Buenos Aires: Voz Activa.

Rabadán, Rosa (1991). Equivalencia y traducción: problemática de la equivalencia translémica inglés-español. León: Universidad de León.

Real Academia Española (rae) (2005). Diccionario panhispánico de dudas. Madrid: Santillana.

Real Academia Española (RaE): Banco de datos (CORPES XXI). Corpus del español del siglo XXI (CORPES). http://web.frl.es/CORPES/view/inicioExterno.view

Toury, Gideon (1995). Descriptive translation studies and beyond. Ámsterdam: John Benjamins.

Turner International Latin America (s. f.). Localization of content. Subtitling-general guidelines: Quick reference guide for audiovisual content. Buenos Aires: Turner International Latin America.

Universidad Nacional Autónoma de México, Corpus del Español Mexicano Contemporáneo (CEMC). http://www.corpus.unam.mx/cemc

Weinreich, Uriel (1954). Is a structural dialectology possible? Word, 10(2-3), 388-400. 